\title{
Transferencias de la viñeta al fotograma. La narración gráfica y sus adaptaciones fílmicas
}

\section{Translations from the vignette to the frame. The Graphic Narrative and its Film Adaptations}

\author{
DAVID GARCÍA-REYES \\ Universidad de Concepción (Chile) \\ mangarcia@,udec.cl \\ ORCID ID: 0000-0003-3445-13
}

\begin{abstract}
Resumen: En cualquiera de sus manifestaciones -la historieta en formato grapa, en álbum de BD (bande dessinée) o bien como novela gráficael cómic opera como texto fuente que proporciona una diversidad de relatos que se convierten en nuevos textos audiovisuales y fílmicos. Este trabajo indaga y examina los procesos operacionales que se generan en las transferencias y reflexiona en torno a cuestiones temáticas, estéticas y argumentales vinculadas a los procedimientos que intervienen en la adaptación de una narración historietística en el medio audiovisual junto al impacto de los cambios y desplazamientos en el relato fílmico.
\end{abstract}

Palabras clave: cómic, novela gráfica, cine de animación, cine de imagen real, adaptaciones filmosecuenciales.

\begin{abstract}
Comic-Book, BD album (bande dessinée) or the Graphic Novel, exemplify some of the Comic formats and are potential source texts that provides the cinema with a variety of stories that become new audiovisual and filmic texts. This paper examines the operational processes that occur in transfers and describes thematic, aesthetic and plot issues related to the procedures involved in the adaptation of a graphic narration in the audiovisual media together with the changes and displacements generated in the film.
\end{abstract}

Key words: Comic, graphic novel, animation cinema, live-action cinema, comic-film adaptations. 


\section{HISTORIETA Y CINE: NARRACIONES CONVERGENTES ${ }^{1}$}

En la edición española de la novela gráfica El curioso caso de Benjamin Button (2009), que adapta el cuento (1922) de Francis Scott Fitzgerald, con guion de Nunzio DeFilippis y Christina Weir y dibujos de Kevin Cornell, el lector puede encontrar un significativo texto sin firmar en el preámbulo de la obra que señala que se trata de «una versión sumamente fiel al relato original. Es de esperar que permita a aquellos que hayan disfrutado de la versión cinematográfica de la historia -una adaptación, esa sí, sumamente libre--acercarse al relato original en un formato ligero y ameno y que no decepcionará a los seguidores de la obra de Scott Fitzgerald» (2009: 6). La opinión prescriptora del prefacio anterior es tendenciosa, pues no solo se refiere al agotador y agotado epíteto de la fidelidad, sino que privilegia la narración de la novela gráfica -ligera y amena, eso sí- que se constituye en una obra más próxima supuestamente al texto literario que el film The Curious Case of Benjamin Button (2008), adaptación dirigida por David Fincher. Este afán por intentar establecer «falsas exactitudes» es redundante en una jerarquización que debería alejarse definitivamente de todo aquello que tenga que ver con los procesos de adaptación, pues ignora el valor de los relatos, independientemente del medio o el formato que adopten estos.

Aunque pueda parecer que está todo dicho cuando abordamos el estudio de las traslaciones fílmicas y cuando se piensa en los procedimientos de la adaptación de un lenguaje como el de la historieta, surge la necesidad de identificar que, aunque se trata de una manifestación visual y narrativa, se suele aproximar formalmente al cine, operándose una serie de cambios que permiten trazar cuestiones diferenciales muy provechosas en el trabajo comparatista. Como Gino Frezza señala, el cine y el cómic son «máquinas comunicativas híbridas, se unen en un solo cuerpo individual y colectivo, orgánico y cultural que hace ver, al completo, la carga de su historia y de su memoria» (2017: 288). Y tiene mucho que ver con la diferenciación que realiza Sergio García Sánchez cuando se ocupa de analizar las unidades estructurales y narrativas del cómic, e infiere, al diseccionar el cómic de bandas, que este no recurre en sí mismo al lenguaje del cine sino al hecho cinematográfico (2000: 157), una apreciación en la que se

\footnotetext{
${ }^{1}$ Artículo realizado en el marco del Proyecto Desplazamientos, emergencias y nuevos sujetos sociales en el cine español (1996-2011) (DENSSCE96-11) financiado por el MICINN (España).
} 
distingue la naturaleza de cada una de las dos formas narrativas, pero que señala también el parentesco que comparten. Ahondando en estos asuntos, pero centrándose en el cine de animación, Scott McCloud señala que la diferencia fundamental entre el cómic y la animación es que la segunda es secuencia en el tiempo, pero no se yuxtapone en el espacio. La distribución de los diferentes planos de una película se proyecta en la pantalla, en cambio las viñetas de los cómics se disponen en un espacio diferente. Por lo que el espacio es para los cómics lo que el tiempo es para las películas (1994: 7).

En los atributos que un film o un cómic presentan como dispositivos narrativos, estos se despliegan narrativamente activando y desencadenando una sucesión de imágenes, generando la posibilidad de incorporar un principio de transformación dentro de esa sucesión narrativa (Gaudreault y Marion, 2004: 66). Prosiguiendo en estas conexiones, Gino Frezza expresa acertadamente que la percepción cognitiva activada en la lectura de un cómic opera en la experimentación intertextual entre los dibujos y los textos, provocando una transformación narrativa en movimiento y, aunque esta sea virtual, resulta medular en la afinidad cine/cómic puesto que

\footnotetext{
la dislocación de la imagen entre el espacio y el tiempo dinámico en el cine, o viceversa entre el espacio segmentado e intersemiótico y el tiempo en el cómic [...] traza la línea cognitiva/emocional y consolida el acervo cultural, gracias al cual surge una serie infinita de relaciones transmediales e intermediales, rigurosas y necesarias, entre estos dos ámbitos de comunicación (Frezza, 2020).
}

Del mismo modo que la literatura presenta una serie de recursos propios, estos mecanismos narrativos y estéticos han resultado trascendentales para la evolución del lenguaje audiovisual, proporcionando no solo una referencia o un sustrato para el cine, sino generando un valioso intercambio también a la inversa, del cine a la historieta. Al igual que ha ocurrido en la literatura y en el cine, la convergencia e interacción entre el cómic y el cine se ha generado periódicamente. Los paralelismos entre el llamado arte secuencial y el cine son procesos que han avanzado desde la constitución normativa tanto del lenguaje audiovisual como de los códigos del cómic, algo que se entiende mejor si pensamos que, históricamente, tanto la historieta como el séptimo arte comparten una cronología casi análoga.

Lo que no ha ido de la mano ha sido la consideración crítica del cine y del cómic; en este punto, la apreciación y aceptación no son equivalentes históricamente. Aunque durante mucho tiempo el cine estuvo relegado culturalmente, el desprecio hacia la historieta ha sido 


\section{David García-Reyes}

una situación mucho más flagrante y dilatada en el tiempo, sostenida por una serie de prejuicios atávicos y carentes de rigor, inherentes a cómo se despliegan las circunstancias de valoración de los ámbitos culturales. A pesar de los abundantes agravios y vilipendios de ciertos segmentos parapetados en el inmovilismo, hay que subrayar que desde los años sesenta del siglo pasado personalidades de distinto cuño se han ocupado de desactivar la tendenciosa oposición al cómic. Un intelectual pionero de esa consideración es Umberto Eco, que se distanció de las asociaciones que deturpaban, con un integrismo indisimulado, la idoneidad o no de unos estudios de cómic que fueron afirmándose a partir de posiciones favorables como las de JeanFrançois Lyotard o Pierre Bourdieu en las décadas finales del siglo XX. La posición de estos pensadores afirma y señala el enorme valor cultural, sociológico y creativo de la historieta desde hace más de cinco décadas, con una nómina que incluye a ensayistas, académicos y críticos que se han opuesto al reduccionismo y al hostigamiento de una manifestación cultural tan válida y notable como cualquier otra. Un debate que en el ámbito hispánico se ha ido ganando a medida que nombres como Carlos Monsiváis, Julio Cortázar, Román Gubern, Antonio Altarriba, Luis Alberto de Cuenca o Ana Merino se posicionaban de forma evidente en el bando de las viñetas, no ya en la defensa del medio, sino en el provechoso y fértil camino que generaba tanto la creación como el estudio de la historieta, asumiendo sin complejos sus valores artísticos y culturales.

En este trabajo se van a exponer y a explorar cuestiones vinculadas a los procedimientos de traslación de las narraciones gráficas al cine. De forma genérica y contraviniendo el título, el estudio no se propone equiparar unidades narrativas, puesto que una viñeta estaría más vinculada a una escena audiovisual que a un fotograma si se quisiera buscar equivalencias. Por eso no se puede simplificar el texto fuente en formato gráfico, puesto que la historieta puede ser susceptible de ser trasladada al cine en cualquier dimensión, desde una grapa ${ }^{2}$ a un

\footnotetext{
${ }^{2}$ Historieta o comic-book que se define por una extensión no mayor a 30 páginas y cuyo formato, cuaderno unido por grapas, viene marcado por un acabado editorial seriado y masivo que suele integrar una colección. Por tanto, suelen ser relatos que presentan una continuidad narrativa a lo largo de sucesivas entregas. La grapa ha vivido una evolución constante, tanto en la calidad de la impresión como en su capacidad para erigirse en un objeto cultural de enorme valor.
} 
álbum de $\mathrm{BD}$ (bande dessinée) $)^{3}$ o a una novela gráfica ${ }^{4}$, como una suerte de storyboard que favorece su adaptación hacia el lenguaje audiovisual.

Por tanto, ajustándose a la propia extensión que el registro exige, se recurrirá a ofrecer una serie de ejemplos para investigar algunas de las diferencias y de las consideraciones que concurren en estos procesos de transferencia de la historieta al cine. Desde una perspectiva sintética y abierta, recorriendo los valores aludidos para poder analizar las adaptaciones que se producen desde las narraciones gráficas a los relatos fílmicos.

\section{CÓMIC VS. CINE}

Salvador Dalí visitaba una tienda de cómics en el París de mediados de la década de 1960 y, en uno de sus alardes como oráculo, vaticinó que los cómics serian la cultura en el año 3794 (Patinax, 1996: 142). La cuestión es que el futuro es pasado, o, mejor dicho, el cómic fue, es y será cultura desde su aparición en el siglo XIX. La anécdota no es baladí si se atiende a las omisiones que se suelen producir en relación a los orígenes del cine.

Es conveniente apuntar que cuando el cinematógrafo echa a rodar, oficiosa y oficialmente, se detecta una primera adaptación. En esos albores fílmicos es cuando el cómic, la historieta o la tira cómica se van a convertir en uno de los primeros textos fuente para la narración cinematográfica. El cortometraje L'Arroseur Arrosé (1895) de Louis Lumière, uno de los primeros films narrativos, adapta las viñetas de la tira cómica Un Arroseur Public (1889) de Christophe, un precursor de la bande dessinée francesa. No resulta extraño en esos comienzos cómo ambos medios se retroalimentan en la gestación de códigos narrativos, propuestas estéticas e inquietudes temáticas compartidas. Del mismo modo, será frecuente la inversión del proceso de adaptación, del cine a la historieta, adaptando seriales o films de lo más diverso en formatos historietísticos con menor o mayor fortuna; un ejemplo contemporáneo es el relato documental Vals con Bashir (Vals Im Bashir,

\footnotetext{
${ }^{3}$ El álbum clásico de historietas del mercado europeo presenta una extensión que varía entre las 45 y las 70 páginas, puede conformar series y entregas, aunque los volúmenes suelen ofrecer historias autoconclusivas.

${ }^{4}$ Narración historietística que suele ser autoconclusiva, cuya presentación y dimensiones alcanzan un paginado que suele estar por encima de las 90 y que, en algunos casos, puede llegar a más de 400 páginas. Esta «feliz aparición en forma de novela gráfica ha permitido consolidar un formato que en realidad era preexistente a su fijación casi canónica como obra de largo aliento» (GarcíaReyes, 2020: 272).
} 
2008) de Ari Folman. La novela gráfica cuenta con libreto de Folman, y David Polonsky, responsable de la animación del film, se ocupa del aparato gráfico. Por eso, las adaptaciones del cine al cómic han sido y son relativamente frecuentes,funcionando como estrategia comercial transmedia antes de que lo transmedial existiese o se acuñase como tal, como evidencian las maniobras comerciales que Hollywood ha emprendido desde la Edad de Oro del cine norteamericano hasta la actualidad, siempre con la pretensión de amortizar todo producto derivado de sus producciones, desde novelas a historietas que transfieren, amplían o sintetizan en sus medios las narraciones cinematográficas. Siguiendo esta línea de estudio, Eduardo Baile López propone una sistematización para aplicar estos análisis del cine al cómic que pueden resultar también útiles invirtiendo el uso de esta (Baile López, 2020: 31), identificando cuestiones vinculadas con los procesos de transferencia de las narraciones gráficas al medio audiovisual. Ese acercamiento puede y debe ampliarse en el caso de las traslaciones filmosecuenciales, dirimiendo cambios operacionales y estructurales en la trama, la narración, la estética, etc. junto al estudio de los procedimientos de traslación, que suelen manifestar la voluntad y aspiración autoriales de las adaptaciones seleccionadas con las que los investigadores trabajan.

El hecho industrial es compartido por parte del cómic y el cine y en una de las diferencias fundamentales con otras artes visuales: ambas muestran la necesidad de una distribución comercial. La historieta se reconoce en su «condición artística al tiempo que necesita su carácter industrial -las peripecias técnicas de su reproductibilidad-》 (Altarriba, 2011: 11). En lo que se refiere específicamente a los procesos de transferencia filmosecuencial y a las proyecciones intermediales, se antoja revelador que, independientemente del origen del texto fuente -novelas o cómics-, los éxitos comerciales de Hollywood cuentan con lo que Robert Stam señala como «paratexto comercial», convirtiéndose un film en una «franquicia o marca, diseñada para generar no solo secuelas, sino productos subordinados dirigidos al consumo, como juguetes, música, libros y otros productos de la sinergia entre los medios» (Stam, 2014: 65).

El largo camino recorrido en las adaptaciones del cómic al cine es secular e implícitamente va asociado al potencial comercial y al progreso tecnológico. En un principio, el cine de animación fue el reducto en el que más desarrollo encontró la adaptación de la historieta, pero esta tendencia no fue, de ningún modo, excluyente a la hora de encontrar ejemplos en el cine de imagen real. También 
conviene señalar a precursores como Émile Cohl o Winsor McCay, responsables de muchas de las traslaciones de sus cómics en el cine de animación de principios del siglo pasado, llevando a cabo la «adaptación de series de historietas que aparecían en prensa a la gran pantalla, aprovechando en muchos casos el concepto común de serial que tan habitual era en el cine americano de entreguerras» (Pons, 2013: 28).

Por otra parte, tanto el cine de animación como el cine de imagen real se aprecian a partir de la percepción de un movimiento continuo para generar la ilusión de movimiento que interpreta el cerebro humano. De forma sintética, se puede señalar que

[e]l cine de animación agrupa las películas creadas a partir de la consecución del movimiento mediante la yuxtaposición de fotogramas que han sido concebidos individualmente. Este concepto hace referencia a un procedimiento de creación, que lo contrapone al cine fotográfico, basado en la captación fotoquímica en un tiempo de una realidad preexistente [...] es un formato, no un género, ni una estética, ni un tipo de películas [...] El procedimiento tradicional de «imagen a imagen» (stop motion o pixilación) está en la base de la propia invención del cinematógrafo, de ahí que, en rigor, la animación sea anterior a 1895 y ya exista en algunas proyecciones de la linterna mágica, las pantomimas luminosas o el teatro óptico de Reynaud (Sánchez Noriega, 2018: 125).

En función de la técnica empleada, se pueden determinar distintos procesos que van desde la animación tradicional a la animación digital por ordenador. El cine animado supone un caudal de formas y de recursos, además, «estudiar las circunstancias históricas de la animación es viajar por una historia paralela del cine [...] la animación ha sido motor de poderosos avances técnicos, de osadas exploraciones formales y de radicales reformulaciones entre creadores y públicos» (Sánchez-Navarro, 2020: 16). Por eso, en estos caminos investigativos resulta esencial, del mismo modo que con el ámbito de la historieta, desterrar prejuicios para avanzar.

Incluso desde la perspectiva de la recepción, cuando Manuel Palacio y Emilio de la Rosa se ocupan del estudio pionero y crítico del cómic versus el cine de animación, apuntan algo particularmente destacable dentro de las industrias culturales españolas. Palacio y De la Rosa señalan la importancia que tiene el capital humano de los creadores de historieta en España y también el potencial de esas obras precedentes para atraer la atención de los espectadores, pues «la veta del cómic constituye usualmente el primer paso para la constitución 
de unos hábitos visuales en el espectador, ya que éste resulta más fácilmente conquistable a partir de unos personajes que le puedan resultar reconocibles y que en muchos casos gozan con anterioridad de popularidad» (Palacio y De la Rosa, 1983: 71).

Volviendo al cine de imagen real, se hace evidente al analizar el éxito de Superman (Richard Donner, 1978) y Batman (Tim Burton, 1989), cómo estos dos títulos abren, cronológicamente, una nueva era en cuanto a la importancia que las adaptaciones filmosecuenciales de superhéroes van a tener en la industria, destacando estos títulos por su vinculación con el sello DC Comics. Una tendencia que se expande tras el estreno de la marveliana X-Men (Bryan Singer, 2000), que señala la explosión del cine de superhéroes y las adaptaciones de cómics de forma sistemática a partir de la configuración de las «directrices que editoriales como Marvel o DC marcan a sus creadores [que] ya no son principios morales que deben cumplir sus personajes, sino esquemas de producción que deben respetar el uso cinematográfico de los personajes y la explotación comercial del merchandising derivado» (Pons, 2013: 33). Por ello, tal y como Jordi Revert considera, la era digital supone un cambio sustancial porque amplía enormemente las posibilidades del cine (2016: 147-148), proyectando intermedialmente el proceso de adaptación de las obras gráficas a los relatos audiovisuales.

Sin embargo, desde los lejanos tiempos de un pionero como Segundo de Chomón, las posibilidades tecnológicas y la innovación cinematográfica han sido una constante, rastreando la multitud de técnicas o trucajes de artífices como Francisco Macián en el ámbito de la animación o la reconocida labor de artesanos tan celebrados y reconocidos como Ray Harryhausen o Emilio Ruiz del Río. No se puede reducir solo al hecho o al potencial tecnológicos el interés que despiertan las traslaciones filmosecuenciales en la actualidad.

En un mercado tan cambiante y supeditado a las nuevas formas de consumo, junto a la renovación y la mejora constante que la tecnología proporciona, la viabilidad de los trasvases de las narraciones gráficas al cine, la televisión o a Internet se presenta como un vehículo más en el que lo transmedial adquiere una importancia superlativa y exhibe unas sinergias múltiples que se han ido gestando a lo largo de las décadas finales del siglo XX y el momento actual. Un ejemplo de lo anterior y de las estrategias transmediales son las adaptaciones de varias obras gráficas del historietista Frank Miller. Sin City (2005), dirigida por Robert Rodríguez y el propio Miller, revisitaba estética y narrativamente los espacios y los personajes de una serie homónima de 
comic books de género noir escrita y dibujada por el historietista. La obra publicada originalmente entre 1991 y 1999, apareció en blanco y negro con insertos cromáticos en rojo o amarillo para subrayar personajes o detalles, deudora de la temática Pulp y del imaginario del singular creador norteamericano. Gracias a la tecnología, Rodríguez y Miller intentaron «traducir» visual y formalmente el impacto de las viñetas de las historietas en un film revolucionario que tuvo continuidad al adaptarse 300 (1998), novela gráfica de Miller en formato apaisado a doble página, cuya traslación fue dirigida por Zack Snyder. En el film 300 (2007), Snyder y su equipo aplicaron diferentes técnicas digitales superponiendo cromas y llevando a cabo un enorme trabajo de postproducción empleando una paleta de colores que enfatizaba las gamas cálidas y ocres, absorbiendo la estética de la novela gráfica para adaptar la particular versión de Miller sobre la Batalla de las Termópilas (480 a.C.) entre los espartanos liderados por el rey Leónidas frente a los invasores persas comandados por el rey Jerjes I. Estos dos largometrajes son referentes de la evolución de uno de los procedimientos que se han ido utilizando para realizar trasvases de las narraciones gráficas al audiovisual, por eso es significativo que el «Digital Cinema now claims an imaginary that was only possible through the static iconography of comic book» (Constandinides, 2010: 84). Por lo que no resulta raro es que las productoras y estudios se lanzarán a abrazar estas explícitas y superdotadas propuestas de un cine digital aquejado de cierta vigorexia. Tanto Sin City como 300 contaron con una secuela y una precuela respectivamente. Partiendo de nuevo de las obras de Miller, los resultados de Sin City: A Dame To Kill For (Robert Rodríguez y Frank Miller, 2014) y 300: Rise of an Empire (Noam Murro, 2014) fueron cuestionables porque, aunque aplicaban las mismas técnicas, narrativa y estéticamente resultaron más un remedo que prolongaciones cualitativas de los dos films originales. La fórmula planteada en el primer film de Sin City parecía agotada en los mismos planteamientos cuando Frank Miller se emancipa como cineasta en The Spirit (2008). La película era una adaptación de las historietas publicadas por primera vez en 1940 por el gran Will Eisner. En el film, el director e historietista se arriesga aplicando lo aprendido en su primera cinta y propone una revisión fallida que estéticamente es muy libre del texto fuente, pero carece de las mejores virtudes narrativas y artísticas de las historietas del propio Miller.

De este modo, se puede percibir la enorme complejidad en relación a todas las cuestiones que intervienen en los procesos de adaptación del cómic al audiovisual, un paisaje en el que se funden e integran muchas características que incumben a todas las industrias 
culturales.Tanto el mundo editorial, como la industria del cine o el sector de los videojuegos se afanan en buscar estrategias transmediales para ofrecer los productos más rentables, prácticas que vienen signadas por lo económico y nos obligan a repensar la adaptación cinematográfica y concretamente a reflexionar en en torno a las transferencias filmosecuenciales: «not only as a process but as a perceptible space due to its instantaneous transactions and interactions with other cultural forms» (Constandinides, 2010: 78).

\section{TRASLACIONES FILMOSECUENCIALES}

El concepto filmosecuencial que presentamos no pretende ser un término totalizador. Al recurrir a este neologismo se puede expresar la cualidad originada desde la narración en cómic y su respectivo trasvase en un relato audiovisual. La formulación de esta conceptualización asume la noción de arte secuencial que popularizase Will Eisner (McCloud, 1994: 5). Además, la naturaleza secuencial es algo que está inserto en el imaginario colectivo, prolongándose en el tiempo distintos modos narrativos que durante siglos conforman «a spatialized narrative where all images appear simultaneously dominated European visual culture; then it was delegated to "minor" cultural forms as comics or technical illustrations» (Manovich, 2001: 205). De esta forma, lo filmosecuencial no excluye otro tipo de manifestaciones gráficas que expresan otras historietas caracterizadas por diversos atributos que no se establecen desde los parámetros de la secuencialidad.

El siguiente apartado resume los procedimientos esenciales que se derivan desde los textos fuente que provienen del medio historietístico y cómo se producen los distintos desplazamientos y transferencias desde la narrativa gráfica a los relatos audiovisuales. Como subraya Raquel Gómez Rosado (2010: 221), el cine se ha aprovechado de la animación para potenciarse creativamente, algo usual en los procesos intermediales y en los procedimientos de traslación de un texto que evoluciona en otro. La traslación no es tanto un mecanismo de conveniencia ni una subordinación propiamente tal, sino la expresión de la esencia de un patrimonio común en el que las manifestaciones artísticas dialogan permanentemente.

\subsection{Tipologías formales}

Las siguientes tipologías se sugieren como un modelo de clasificación, no persiguen establecer una jerarquización canónica, sino un planteamiento taxonómico para favorecer el análisis a partir de 
cuatro grandes categorías. A la hora de configurar estas tipologías se ha tenido en cuenta el acabado formal de las mismas, asumiendo las características visuales de una adaptación que se constituye como tránsito de un medio a otro. En la descripción de cada una se argumentan genéricamente los principales atributos derivados del procedimiento óptico o formal que se sigue en una transferencia del cómic al audiovisual. No es el objeto de la propuesta entrar a dirimir o dilucidar los diferentes enfoques autorales, estéticos, temáticos o narrativos que, del mismo modo que en las traslaciones filmoliterarias, se pueden apreciar y establecer en cada adaptación y que son, necesariamente, materia para futuras investigaciones.

\subsubsection{Adaptación filmosecuencial mimética en el cine de animación}

La adaptación filmosecuencial mimética de una obra gráfica es producida por el cine de animación. Esta modalidad se caracteriza porque presenta los mismos atributos que constituyen la naturaleza gráfica del cómic fuente del que se sirven para llevar a cabo la adaptación. Este tipo de traslación implica una estrategia de elaboración y producción que, ópticamente, emana de un resultado mimético que consigue animar y transferir con literalidad el aparato gráfico de la obra matricial.

Se pueden encontrar ejemplos de este tipo en la transposición del cómic Cuando el viento sopla (When the Wind Blows, 1982) de Raymond Briggs, una brillante parábola gráfica profundamente antibelicista frente a la hecatombe nuclear que cuenta el film homónimo (1986) de Jimmy T. Murakami. La cinta británica ofrece un «catálogo de técnicas para explorar distintas estrategias expresivas y reflejar y provocar diferentes estados de ánimo» (Sánchez-Navarro, 2020: 115), consiguiendo trasladar con acierto y maestría el aparato gráfico, la paleta cromática junto al espíritu visual y ético del cómic de Briggs. El paso del tiempo y la guerra también son temas fundamentales en la narración gráfica Persépolis (2000-2003), obra autobiográfica de la artista iraní Marjane Satrapi, que toma el testigo del cómic y adopta la estética y bicromía del blanco y negro en Persépolis (Persepolis, 2007), exitoso film francés dirigido por Satrapi junto al realizador Vincent Paronnaud, consiguiendo una animación minimalista que transpone sabiamente el texto fuente.

La adaptación filmosecuencial mimética logra transferir y sistematizar visualmente las narraciones gráficas precedentes, destacando también el largometraje español Arrugas (2011), dirigido por Ignacio Ferreras a partir de la novela gráfica Arrugas (2007) de Paco 
Roca, que se convirtió en un verdadero hito dentro de la nueva ola del cómic español. En la obra, Roca pone el foco en Emilio, Miguel, Antonia y un grupo de ancianos que viven en una residencia geriátrica. Con grandes dosis de humor y empatía, el creador valenciano otorga visibilidad a la soledad de la llamada Tercera Edad y a la enfermedad de Alzheimer. La sensibilidad de la novela gráfica y su calidad narrativa hicieron que Roca ganase el Premio Nacional del Cómic (2008) y también mostró las posibilidades que tenía la obra de ser adaptada al cine. Ferreras se encargó de la dirección y contó para el guion y el diseño de los personajes con el propio Roca. Además, se puede inferir que la banda sonora y el doblaje son los elementos más notorios de este desplazamiento secuencial. Muy alejado de los relatos intimistas señalados, hay que apuntar la irreverente The Haunted World of El Superbeasto (2009), film de animación de Rob Zombie que se ocupa de adaptar los comics books del mismo título (2007), siendo el polifacético Zombie el autor del libreto libr que cuenta con dibujantes como Kieron Dwyer, Tony Moore, Alex Horley y Dan Brereton, responsables de la concepción visual de la cinta animada de Zombie. En estos ritos de pasaje miméticos de la novela gráfica al cine conviene rescatar el trabajo del también músico Fermín Muguruza, que firma como director la adaptación de la novela gráfica Black is Beltza (2014), sugerente obra con guion del propio Muguruza y de Harkaitz Cano junto a los dibujos de Jorge Alderete. Este arriesgado cómic y dilatado proyecto transmedia cuenta con un poderoso aparato gráfico y estético diseñado por Alderete, relato que recorre varias décadas y latitudes del siglo XX. Manex, el protagonista, vive cambios políticos y sociales desde mediados de los sesenta y se siente comprometido en las disputas por combatir la injusticia, mostrando el film la lucha frente a las desigualdades globales. Todo ello fue un caldo de cultivo que empujó a Muguruza a dirigir Black is Beltza (2018) que, aunque a veces resulta demasiado esquemática, consigue elaborar una animación con un ritmo narrativo tan dinámico como el cómic fuente y trasladarnos al ambiente y a la estética de la novela gráfica.

\subsubsection{Adaptación filmosecuencial animada reformulada}

La adaptación filmosecuencial animada reformulada se define por mostrar rasgos o características presentes en la narración gráfica precedente, pero expone permutas formales específicas a la hora de abordar la representación, características que se pueden manifestar en un cambio cromático o en el diseño de espacios y personajes. De esta manera se puede considerar una reformulación del aparato gráfico 
precedente, incidiendo en el cambio operativo al trasladar una historieta o una tira cómica publicada en bitono o en blanco y negro. En este sentido hay que apuntar que al pasar de la bicromía a la adición de color en unanarración audiovisual animada es un procedimientofrecuente desde que a mediados de la década de 1930 se popularizase el uso del coloren el cine de animación estadounidense. Además, la adaptación filmosecuencial animada reformulada puede recoger el cambio ideográfico en la representación y el re-diseño del conjunto en algunos apartados dentro del relato animado. Dentro del mismo esquema expuesto se pueden incluir las cintas de animación que se desarrollan a través de la stop motion o animación en volumen, pero también las que aplican la tecnología digital a partir del empleo del CGI (Computer Generated Imagery), de las herramientas tridimensionales o 3D, y también del uso de cualquier técnica de captura de movimiento, entre las que se puede señalar el rotoscopiado ${ }^{5}$, configurando una pátina y un acabado completamente distintos con un tempo narrativo que aproxima a muchas de estas cintas animadas al ritmo de un film de imagen real.

La idea de la reformulación animada a partir de un original gráfico suele producirse cuando se procede a incorporar el uso del color, puesto que el diseño de los personajes puede ser transferido integralmente en la traslación filmosecuencial animada, pero la añadidura cromática y la creación de los ambientes y de los espacios quedará profundamente influida por la incorporación del color. Dentro del cómic underground, la tira cómica Fritz the Cat (1965-72) de Robert Crumb presentaba a Fritz, un felino descarado y ávido de experiencias vitales extremas durante la época del Movimiento Hippie y el auge de la contracultura estadounidense de la década de 1960. Fritz es un «personaje hipócrita, oportunista y procaz, en un contexto urbano degradado, y sobre el fondo continuo del consumo desaforado de drogas y la promiscuidad sexual» (Sánchez-Navarro, 2020: 70). Crítico con la idealización de estas corrientes, Crumb concibió el personaje dotándole de un cinismo distanciado junto al afán del personaje por experimentar con las drogas o el sexo. Las trazas de Fritz son las de un gato antropomorfo en blanco y negro en pequeñas historias, como la mayoría de las tiras cómicas. Los dos elementos anteriores cambian en el film Fritz the Cat (1972), dirigido a un público adulto, puesla cinta de Ralph Bakshi hacía del uso del color y de una trama lineal dos de los

\footnotetext{
${ }^{5}$ Procedimiento que, a partir de la filmación de una de imagen real, emplea las tomas que se transfieren por medio de la animación y que puede configurar, desde el movimiento de lo filmado, acciones audiovisuales más complejas.
} 


\section{David García-Reyes}

atributos más destacables. La película se imbuía de la naturaleza anárquica del cómic fuente, pero sin proyectar las dosis de ironía que trascendían en la obra de Crumb. No obstante, el largometraje funcionó como un demoledor retrato de la época y fue la primera película animada en recibir la calificación X como cinta de contenido pornográfico en Estados Unidos. La provocación que llevaba asociada convirtió la película en un éxito comercial que llevó al productor Steve Krantz a financiar The Nine Lives of Fritz the Cat (1974) de Robert Taylor, secuela que se componía de historias cortas impregnadas del ritmo lisérgico de su precedente, aunque lejos narrativamente del primer título de Bakshi, que evitó involucrarse en el mismo.

Desde una latitud más sureña, otras muestras de adaptación filmosecuencial animada reformulada son las traslaciones de Mafalda, la tira cómica argentina que se publicó entre el 29 de septiembre de 1964 y el 25 de junio de 1973. El personaje y las tramas ideadas por el historietista argentino Joaquín Salvador Lavado «Quino» aparecían en blanco y negro, en cambio la película Mafalda (1982) de Carlos D. Márquez optó por aplicar color al relato. Márquez integró varios segmentos de la serie animada original de principios de los años 70 para armar el largometraje. Este empleo del color tuvo continuidad en la serie Mafalda (1993), coproducción televisiva entre Cuba y diferentes televisiones autonómicas de España, dirigida por el historietista y animador cubano Juan Padrón a partir de la obra de Quino.

Sin abandonar las décadas de los setenta y los ochenta, pero dentro de la industria japonesa, podemos encontrar Lupin III: el castillo de Cagliostro (Rupan sansei: Kariosutoro no shiro, 1977), que se trata del primer largometraje de Hayao Miyazaki. Miyazaki aceptó el encargo de adaptar el manga Lupin III (1967-1972) del mangaka Kazuhiko Katô más conocido como «Monkey Punch», que a su vez es una revisión moderna del personaje Arsenio Lupin, el ladrón de guante blanco imaginado por el escritor francés Maurice Leblanc. Lupin III ya se había convertido en un célebre personaje de animación en televisión e incluso contaba con dos largometrajes previos de imagen real y de animación, respectivamente. En su debut cinematográfico, Miyazaki se encarga de dirigir una película en color en contraste con la bicromía del manga de Monkey Punch. El diseño de los vehículos y las escenas de acción son de lo mejor de la película, que funciona como entretenimiento masivo y evidenció la destreza de Miyazaki coordinando a su equipo, más aún teniendo en cuenta las intenciones de los productores de explotar a toda costa el éxito de un personaje popular. 
No obstante, el director no tardaría en levantar su segundo largometraje, un proyecto tan personal como lleno de muchas de las constantes estéticas y temáticas del cineasta japonés y que sigue siendo hoy en día una notable reformulación animada. Nos referimos a Nausicaä del Valle del Viento (Kaze no Tani no Naushika, 1984), film que adapta parte del manga del mismo título que Hayao Miyazaki publicó en siete volúmenes entre 1982 y 1994. La complejidad del cómic frente a su traslación es proporcional a la dimensión del relato audiovisual. Obviamente, la trama expandida del manga es producto del propio desarrollo que Miyazaki empleó para elaborar su obra gráfica y también se percibe la propia retroalimentación que tuvo el trabajo de animación volcada en una serie de historietas que traslada a los lectores a ese mundo futuro tóxico y postapocalíptico en el que se desarrolla la narración. En cuanto a los cambios operacionales del cómic al cine, además de pasar de la bicromía en blanco y negro de las viñetas al uso del color en la película, es destacable el protagonismo de Nausicaä, precedente de los grandes personajes femeninos del director, que si bien estaba muy presente en los primeros volúmenes del manga, crece en su definición mítica a partir de la espectacularización establecida por la película. Encontramos un caso parecido con el largometraje Akira (1988) de Katsuhiro Ôtomo. El director, como Miyazaki, era el autor del manga homónimo publicado entre 1982 y 1990. La obra, editada originalmente en blanco y negro, fue adaptada a la pantalla grande por el director y mangaka japonés antes de la conclusión argumental del cómic. El creador nipón se adapta así mismo en todo un logro del cine de animación.

La calidad de este poderoso relato de ciencia ficción en un formato u otro es autónoma e independiente porque, del mismo modo que en el segundo film de Myazaki, la película Akira supuso para Ôtomo un punto de inflexión en la dirección del desenlace de su saga gráfica, exponiendo cómo la mediación de un lenguaje a otro, desde la expansión al desarrollo del propio texto fuente, seguía vivo e inconcluso mientras se gestaba su traslación fílmica. Muchos de los progresos técnicos en materia de animación de Akira cristalizaron en otro film fundamental del anime como Ghost in the Shell (Kôkaku Kidôai, 1995), película de Mamoru Oshii que adapta el manga del mismo título (1989-1990) de Masamune Shrirow. Tanto el manga como la película han sido objeto de revisión y expansión por parte de Shirow y Oshii en nuevas entregas en forma de cómic y relatos audiovisuales e incluso una adaptación estadounidense de imagen real (2017), producciones que enfatizan el carácter transmedia del mundo de ciencia ficción creado por el mangaka. Oshii, responsable de un estilo visual repleto 


\section{David García-Reyes}

de intertextos, no solo presenta un cambio en la diferenciación cromática del cómic en blanco y negro, sino que profundiza en los temas y en la responsabilidad autoral de entregar una atmósfera propia a la cinta. Algunas de estas características se pueden observar en otra adaptación de un manga de Shirow como es Appleseed (Appurushîdo, 1985-1989), el film del mismo título (2004), dirigido por Shinji Aramaki. Anteriormente, el cómic había sido adaptado en 1988 por Kazuyoshi Katayama en animación 2D. Aramaki se encarga de coordinar a un equipo en una traslación tridimensional de la historia de ciencia ficción sobre cuestiones existenciales en un contexto ciberpunk donde la biomecánica y la inteligencia artificial parecen imponerse a la humanidad. El film cuenta con varias secuelas, generando una propuesta visual retomando el manga como texto preexistente peroplanteando una estética muy distinta frente al cómic matricial. En esta misma línea, la tecnología 3D se encarga de llevar a otra instancia el cine de animación y las traslaciones del cómic al cine. Uno de los ejemplos más notorios es Las aventuras de Tintín: El secreto del Unicornio (The Adventures of Tintin: The Secret of the Unicorn, 2011), dirigida por Steven Spielberg y producida por Peter Jackson, aplicando la captura de movimiento, yendo más allá al adaptar al célebre personaje de la $\mathrm{BD}$ belga de Hergé e integrando tres volúmenes de la serie con El cangrejo de las pinzas de oro (1941), El secreto del Unicornio (1943) y El tesoro de Rackham el Rojo (1943), en los que se invierte «el orden de las dos primeras historias, añadiendo algunos pasajes de acción que [...] Hergé resolvía con una elipsis o paralipsis y, sobre todo, introduciendo un tercer acto cargado de acción y totalmente inventado por los guionistas» (Aertsen, 2021: 58).

En el contexto hispánico se pueden apreciar dos ejemplos en cuanto a la aplicación de la tecnología 3D en la evolución del cine de animación. En primer lugar, se puede citar Boogey, el aceitoso (2009) de Gustavo Cova. Este film es la primera producción tridimensional argentina, coproducida por México, que lleva a la pantalla grande la tira cómica sobre el implacable y sardónico sicario creado por el escritor e historietista Roberto Fontanarrosa, publicada entre 1972 y 1995. Al margen de la paleta de colores, la película es un relato lineal que ha perdido parte de la corrosiva crítica de Fontanarrosa en una historieta latinoamericana que aborda sin rubor el intervencionismo político y las atrocidades generadas por las desigualdades y que, a pesar de todo, suscita el ácido humor negro del creador rosarino. En España, y con mayor audiencia, encontramos a Mortadelo y Filemón, los célebres personajes concebidos por Francisco Ibáñez, publicados por 
primera vez en enero de 1958, que siguen estando muy presentes en el mercado editorial, con nuevos lanzamientos que obtienen el beneplácito del público, sintomático de la trascendencia de ser una de las historietas más adaptadas del cine español. Al margen de las traslaciones animadas para televisión de Rafael Vara (1969-1970) y Claudio Biern Boyd (1994) - que seguían en mayor o menor medida el espíritu gráfico y anárquico de las descacharrantes aventuras de estos particulares agentes de inteligencia-, en la pantalla grande las historietas de la pareja cobran una enorme importancia cuando asume el proyecto de adaptarlas a imagen real el director Javier Fesser. Fesser consigue un enorme éxito con La gran aventura de Mortadelo y Filemón (2003), seguida por Mortadelo y Filemón. Misión: salvar la Tierra (Miguel Bardem, 2008). El díptico de imagen real textualizaba los desopilantes relatos de Ibáñez gracias al uso del CGI y de un elenco que encarnaba con desigual idoneidad los rasgos de los personajes de cómic. De nuevo Fesser retomaría los personajes en otro largometraje de animación 3D, con Mortadelo y Filemón contra Jimmy el cachondo (2014), el cineastas proyecta el universo de Ibáñez en una propuesta independiente que se vale de la tecnología y avanza en los procesos de traslación filmosecuencial.

Por dar un último y señero ejemplo reciente de la tipología de la adaptación filmosecuencial animada reformulada, encontramos la adaptación de Buñuel en el laberinto de las tortugas (2008) de Fermín Solís. Publicada originalmente en blanco y negro por el sello Astiberri, la novela gráfica de Solís buceaba en la gestación del film documental Las Hurdes, tierra sin pan (1933) de Luis Buñuel. El historietista extremeño indaga en la creación de la película del director aragonés y señala el valioso concurso en la empresa del productor de Las Hurdes, Ramón Acín. Acín fue un artista y pedagogo libertario español, amigo de Buñuel, que Solís recupera como personaje de enorme relevancia dramática. Durante la prolongada génesis del film Buñuel en el laberinto de las tortugas (2018) de Salvador Simó, la producción se dilata en el tiempo, saliendo a flote gracias al empeño de la productora extremeña The Glow, liderada por José María Fernández de Vega. El proyecto echa a andar y se convierte en uno de los mayores éxitos del cine animado español. Empleando técnicas de animación tradicional, se trata de una la traslación de la obra de Solís que expande cromáticamente el universo ficcional del texto fuente, potenciando descriptivamente los espacios de ambientación y subrayando decisivamente al personaje de Acín. Hay que destacar, que antes de llegar al resultado del logrado largometraje de Simó, Fernández de Vega dirige el cortometraje Buñuel en el laberinto de las tortugas, que él 
y su equipo concluyen en 2015, pero que no se llega a estrenar hasta 2020 para no interferir en la producción y promoción de la película, de la que es un ensayo fundamental durante el desarrollo del largo. El corto de Fernández de Vega se ocupa de atrapar en blanco y negro la naturaleza onírica de la novela gráfica en lo que podría definirse como una traslación filmosecuencial mimética. De forma minimalista, es un esbozo que marca muchas de las pautas del film de Simó. En este proceso de tránsitos, en una estrategia de hechuras transmediales, después del estreno de la película, la novela gráfica fue reeditada en 2019 por Reservoir Books, siendo el principal reclamo de lanueva edición el uso de la misma gama de colores de la película homónima).

\subsubsection{Adaptación filmosecuencial híbrida, yuxtaposición de imagen real y animación}

La adaptación filmosecuencial híbrida, que integra la yuxtaposición de imagen real y animación, puede emplear algunas de las técnicas ya señaladas con anterioridad, alternancia que resultó un recurso frecuente en muchas de las cintas de imagen real producidas por el estudio Disney durante las décadas de 1960 y 1970 que, además, servían para retroalimentarse de films precedentes, en una estrategia que la productora del ratón Mickey supo explotar comercialmente. Al margen de Disney, el uso de la animación para converger en propuestas de imagen real se ha ido incorporando como insertos que favorecían la narración, siendo uno de los ejemplos más sobresalientes el fragmento animado de Kill Bill Volume 1 (2003) de Quentin Tarantino. La escena en cuestión cuenta a modo de flashback el origen y el pasado de la mafiosa O-Ren Ishii (Lucy Liu), con secuencias anime producidas por el estudio de animación japonés Production I.G. En la idiosincrasia de una adaptación de cómic al cine que cuenta con esta doble naturaleza, imagen real e imagen animada, existe un aspecto que evoluciona hacia propuestas mucho más complejas, algo que ya se ha señalado con anterioridad: el uso de las propias viñetas y de la representación de los personajes de los cómics fuente, como en Sin City o 300, pero también para crear o recrear estéticamente un mundo ficcional y una atmósfera que evoca irremisiblemente a la obra precedente.

De esta manera, se pueden encontrar otros precedentes de la yuxtaposición de imagen real y de la imagen animada en cintas como Heavy Metal (1981) de Gerald Potterton, definida por Jordi SánchezNavarro como la «ilustración del espíritu de una época en la que aún se agitan algunas energías de la contracultura de los sesenta y se 
respiran nuevos aires punk» (Sánchez-Navarro, 2020: 103). Lacinta de Potterton contribuye a la convergencia de registros visuales, consiguiendo epatar con una propuesta adulta, convertida en una antología que se permite rescatar relatos secuenciales de la revista que da nombre al film y que, entre otros, proyecta los universos ficcionales y estéticos de genios de la viñeta como Richard Corben o Moebius.

Heavy Metal señalaba un inventario de las posibilidades comerciales de expandir los relatos y un precedente de los factores transmedia, algo de lo que se ocupa también Cool World (Ralph, Bakshi, 1992), film presentado como un artefacto transmedial con precuelas de cómic que se elaboraron a medida que la cinta se estaba gestando. La película de Bakshi se convirtió en un fracaso comercial y gran parte del mismo se debió a las injerencias de los productores y a no saber vender una trama que transitaba entre dos dimensiones cinematográficas, la real y la animada, de forma irónica y llena de juegos narrativos. Retomando la producción del cómic underground estadounidense, American Splendor (2003) de Shari Springer Berman y Robert Pulcini, a medio camino entre el documental y la ficción cinematográfica, aglutina insertos y recursos gráficos que textualizan el cómic y que dan cuenta de la vocación híbrida y disruptiva de una película inclasificable de enorme valor. Como los comic books en los que se basa, el film muestra lo convencional y lo eleva a la categoría de extraordinario. Esto último no resulta raro si pensamos que Harvey Pekar, el creador y guionista de los cómics de American Spledor (1976-2008). En esta saga gráfica, Peakar relata la mitad de su vida, seleccionando la película fragmentos de los cómics. La narración expone la existencia, aparentemente gris y huraña, de Peakar y de las diferentes vicisitudes que vive como empleado del archivo de un hospital de Cleveland, clamando por su precaria salud y describiendo las tribulaciones emocionales y sentimentales del autor/protagonistajunto a Joyce Brabner, su tercera y última esposa. Pekar y Brabner tienen una presencia destacable en el film y señalan cómo el guionista se convirtió en una de las voces alternativas del cómic independiente de Estados Unidos, una posición favorecida por su colaboración con Robert Crumb, siendo este el principal dibujante de la serie.

Otra arriesgada propuesta en clave documental es María y yo (2010) de Félix Fernández de Castro, adaptando la obra gráfica homónima (2007) del historietista Miguel Gallardo sobre algunas de sus vivencias junto a María, su hija autista. El uso de los insertos de la animación resulta muy funcional (Bórquez, 2021) para la representación de un tema tan comprometido, sirviendo para atenuar con humor la fuerza dramática de la historia y normalizando el TEA (Trastorno del 
Espectro Autista). En esta misma línea, a la hora de yuxtaponer el uso de imagen real e imagen animada, pero cambiando de géneros, aparece Pollo con ciruelas (Poulet aux prunes, 2011) de Vincent Paronnaud y Marjane Satrapi. A partir de la novela gráfica homónima en blanco y negro de la propia Satrapi, el film intercala la imagen real evocando un cuento lleno de las complejidades de la geopolítica histórica de Oriente Medio con algunas escenas animadas en color, junto al inconfundible estilo de la dibujante. Cambiando de tercio, en el cine estadounidense se puede apreciar la adaptación de la serie de cómics Scott Pilgrim (2004-2010), del historietista canadiense Bryan Lee O'Malley, en el film Scott Pilgrim contra el mundo (Scott Pilgrim vs. the World, 2010) de Edgard Wright, que recurre sabiamente a textualizar audiovisualmente onomatopeyas o recursos gráficos del cómic y el videojuego, en un desplazamiento singular y muy sugestivo.

\subsubsection{Adaptación filmosecuencial de una obra gráfica en una cinta de imagen real}

La adaptación filmosecuencial de una obra gráfica en una cinta de imagen real se caracteriza porque, aun partiendo de la narrativa gráfica, puede plantear su transferencia argumental en cualquier cinta o pieza audiovisual realizada en imagen real. Suele ser la más usual y convencional de las adaptaciones filmosecuenciales desde una consideración formal, pues toma un cómic o una novela gráfica como un texto fuente y lo usa como un libreto que sigue dependiendo de las intenciones que se asuman a la hora de materializar el relato audiovisual.

$\mathrm{Al}$ elaborar estas adaptaciones, se equiparan conceptos precedentes a los procesos de transferencia filmoliterarios, resultando decisiva la adecuación o pertinencia de la adaptación en cuanto a la elección del elenco o de la ambientación, el peso de los detalles y el desarrollo del texto fuente en la narrativa audiovisual, que suelen contar con una preeminencia manifiesta, puesto que está muy presente el diseño y configuración de ciertos personajes, sobre todo en el caso de los superhéroes, que suelen conservar muchos de los atributos físicos y morales de los cómics, características configuradas a lo largo del tiempo que permean así en el imaginario colectivo de un gran número de espectadores a nivel global.

No obstante, al margen de esa nutrida nómina de superhéroes, antes de estos, estuvieron los héroes. Al remontarse al Hollywood de los cincuenta, encontramos una de las más notorias traslaciones filmosecuenciales de imagen real con El príncipe Valiente (Prince Valiant, 
1954) de Henry Hathaway, superproducción de capa y espada en cinemascope y technicolor, que trasladaba las aventuras del personaje de Valiente, príncipe escandinavo en la corte del Rey Arturo. La serie fue publicada por primera vez en 1937 por el historietista Harold Foster.

En cuanto a los superhéroes, suele ser el caso más paradigmático a la hora de ver adaptados sus relatos gráficos en el audiovisual, todo un género o subgénero en sí mismo que cuenta con la disputa de DC Comics y Marvel entre los lectores por parte de estos dos sellos editoriales estadounidenses. Ambas corporaciones han desarrollado su faceta como empresas productoras, compitiendo también en el cine y desarrollando activamente las sagas de Superman, Batman, La Liga de la Justicia o Spiderman, Iron Man, X-Men y Los Vengadores, por citar algunos ejemplos.

Al margen de los títulos de superhéroes, hay que señalar propuestas interesantes que, en su concepción, persiguen no solo adaptar los cómics sino ofrecer, desde estos desplazamientos, relatos que estimulen los procesos de traslación filmosecuencial. Entre esos films, destaca Dick Tracy (1990) de Warren Beatty, que es uno de los casos más singulares de las filmografías presentadas. Desde su posición como producción dentro del sistema de estudios, la cinta cuenta con la pretensión de emular a partir de los departamentos de maquillaje, vestuario y las escenografías más pulp y más kitsch imaginables, la imagen de las portadas y la fisonomía de los personajes de los cómics de Dick Tracy creados en 1931 por Chester Gould. Beatty no solo realizó un homenaje al personaje, sino que dirigió un film que resultó incomprendido en su momento y que, retrospectivamente, es realmente interesante en su transitar del comic book homónimo al cine, muy distinto de la hibridación animación-imagen real de Cool World o Who Framed Roger Rabbit (Robert Zemeckis, 1988).

El cine norteamericano, ávido de historias, encontraría un filón en los espacios del cómic de género: de esta manera sobresale Una historia de violencia (A history of Violence, 2005) de David Cronenberg, que parte de la novela gráfica Una historia violenta (A history of Violence, 1997), escrita por John Wagner y dibujos de Vincent Locke. La obra de Wagner y Locke es un singular cómic noir lleno de intertextos y un relato renovador del género dentro de la narrativa gráfica. La historia sobre el pasado encubierto del protagonista vuelve a escena y sirve de esquema para desarrollar el guion del film, que cuenta con detalles extraídos directamente de la novela, como la fisonomía del rol de Carl Fogarty (Ed Harris), caracterizado con los rasgos del personaje análogo del cómic. En una línea similar, los rincones oscuros y la génesis de un asesino en serie son tratados por el historietista Derf Backderf en su 


\section{David García-Reyes}

debut dentro de la novela gráfica. Todo psicópata tiene un pasado, un lugar de origen, una familia y unos amigos o conocidos. el entorno de un psicópata no tiene por qué ser inhóspito o sórdido, tal y como muestra My friend Dahmer (2012), que relata en blanco y negro las propias experiencias del autor al lado de su compañero de clase Jeffrey Dahmer.Dahmer se convertiría luego en el asesino en serie conocido como «el caníbal de Milwaukee«». En la película Mi amigo Dahmer (My friend Dahmer, 2017), el director Marc Meyers, del mismo modo que Backderf, intenta acercarse a aquello que hace más humano a Dahmer y sus prácticas más extravagantes, anécdotas subrayadas en el film, planteando al final una resolución distinta que la del texto fuente.

Los tránsitos del cómic en el cine europeo van a surtir de propuestas muy diversas, desde las traslaciones fílmicas en imagen real o animación de sagas como Astérix el Galo, Lucky Lucke o Teniente Blueberry, a la novela gráfica en blanco y negro Sordo (2008) con arte de Rayco Pulido y guion de David Muñoz, ambientada en 1944 con un grupo de maquis, siendo adaptada por la película del mismo título (2019) de Alfonso Cortés-Cavanillas. La historia sobre estos guerrilleros y últimos resistentes contra el franquismo en la postguerra adquiere un tono distinto en el relato audiovisual en color, con una primera parte del metraje planteada como un western, algo ajeno al cómic fuente, que después explota en una atmósfera de pesadilla deudora de los films españoles de Guillermo del Toro. Los cambios operacionales en este tipo de adaptaciones se pueden apreciar en la película La vida de Adèle (La Vie d'Adèle, 2013) de Abdellatif Kechiche, distanciándose frente al sensible e intimista relato de la novela gráfica El azul es un color cálido (2010) de Julie Maroh. La adaptación cuenta con numerosas licencias, centrándose en una visión hipersexualizada de Kechiche al mostrar las relaciones de dos jóvenes mujeres. La disparidad entre una obra matricial y su adaptación es frecuente, conllevando dificultades que crecen a la hora de adaptar una novela gráfica. De esta manera, la película de imagen real La profecía del armadillo (La profezia dell'armadillo, 2018) de Emanuele Scaringi contrasta con el estilo desenfadado de la novela gráfica italiana (2011) del mismo título de Zerocalcare. El cómic en blanco y negro, lleno de elementos autobiográficos, introduce a un enorme armadillo que funciona como la voz de la conciencia del protagonista, atribulado al enterarse de la pérdida de un ser querido. La película está más volcada en orientarse a su potencial público juvenil que a proyectar autoralmente el relato secuencial, reducido a la cita de ese 
aparatoso armadillo que parece una versión moderna y estrafalaria del Grillo parlante del Pinocchio de Carlo Collodi.

En un registro muy distinto, se puede señalar la adaptación de los comic books de Watchmen (1986-1987), con guion de Alan Moore y dibujos de Dave Gibbons, una historia de ciencia ficción con una trama densa en torno a la turbulenta política de los años ochenta, muy presente en esta parábola distópica. Un mundo como el ideado por Moore y Gibbons suscitó el interés de varios cineastas, por lo que después de 300, Zack Snyder la consideró una posibilidad tangible y asumió el reto de trasladar las viñetas al cine, con la oposición de Moore-siempre beligerante en cuestiones vinculadas a la traslación de sus cómics al audiovisual-, y se encargó de proyectar la atmósfera en una cinta de imagen real en la que se tuvo muy presente el diseño de los cómics en una exhaustiva planificación de las secuencias según las viñetas, la ambientación y la selección del elenco en Watchmen (2009). El resultado puede ser discutible, pero las intenciones de Snyder son loables, del mismo modo que la secuela televisiva Watchmen (2019), que sitúa la historia tres décadas después de los sucesos de la obra gráfica.

Recurriendo de nuevo a uno de los autores más reconocidos del cómic independiente estadounidense, Wilson (2017) de Craig Johnson, llevaba a la pantalla grande la hilarante historia original de Daniel Clowes sobre un misántropo que descubre que es padre y decide buscar a su hija. La cinta trasladaba la novela gráfica del mismo nombre (2010) y que eratoda una radiografía de la condición humana. Los segmentos secuenciales se integraban linealmente en el film y ofrecían un acercamiento al texto fuente, algo que ocurría en otra obra de Clowes que había sido adaptada al cine con anterioridad. Ghost World (2001) de Terry Zwigoff, adaptaba los comic books de Clowes del mismo título publicados entre 1993 y 1993; en este caso, el film y los cómics mostraban las disyuntivas de dos jóvenes mujeres al enfrentarse a la transición de la juventud al mundo adulto, plagados de referencias de la cultura popular.

\section{CONCLUSIONES}

Las tipologías presentadas son propuestas generales con las que ir estableciendo un esquema para poder aplicar a los análisis y sus respectivos elementos, características que intervienen en todo estudio comparatista y pretenden fortalecer este tipo de trabajos por medio de la sistematización planteada.

$\mathrm{Al}$ examinar los procesos de traslación filmosecuencial se aprecia que en el ámbito de la animación los manuales teóricos para llevar a 


\section{David García-Reyes}

cabo una adaptación, literaria o gráfica, no tienen la necesidad de ocuparse de estas. Ese es el caso del volumen Guionización y desarrollo de la animación (2006) de Jean Ann Wright, en donde apenas se mencionan los procesos de traslación del texto literario y mucho menos se encuentra alusión alguna a la adaptación de una narración gráfica en una cinta animada. Algo que contrasta con algunos de los textos de introducción al guion más célebres, como las obras escritas por Syd Field o el manual de guion de Linda Seger, cuyo significativo título es $E l$ arte de la adaptación. Teniendo en cuenta el enorme esfuerzo que supone la elaboración y puesta en marcha de una película animada, desde la escritura del guion a las distintas etapas de producción, resulta llamativo observar cómo en un libro cuyo objetivo es preparar a guionistas especializados en animación se omita algo tan fundamental. Esto nos empuja a pensar en la necesidad de abordar los procesos de adaptación de la narración gráfica al cine, dado que en todo procedimiento de transformación de un texto fuente o de una obra matricial se activan mecanismos de cambio que amplían y ensanchan el espacio del relato, multiplicando la capacidad de narraciones preexistentes a la hora de generar nuevos productos, autónomos e independientes. Por lo anterior,resulta tan estimulante poder aplicar un estudio comparatista para seguir profundizando en aquello que resulta realmente significativo, pues

todas las películas, no sólo las adaptaciones literarias, los remakes y las secuelas están mediatizadas por la intertextualidad y la reescritura [...] «obras derivadas», por ejemplo, obras que «reformulan, transforman o adaptan» algo que existía con anterioridad. Sin embargo, en cierto sentido las adaptaciones ponen de manifiesto lo que es verdadero para todas las obras de arte: el hecho de que todas son «derivadas» en cierto sentido. Así, el estudio de la adaptación tiene un impacto potencial sobre nuestro entendimiento de todas las películas (Stam, 2014: 102).

No obstante, la profusa tendencia de adaptar cómics en textos audiovisuales concita una reflexión que podría tener múltiples puntos de vista, entre las que se encuentra la eclosión de la novela gráfica a nivel global y también el impacto que los cómics asociados a la cultura mainstream han tenido y tienen en la cultura popular. Estos dos factores por sí mismos no son los únicos motivos que explican el interés de los creadores audiovisuales en el cómic. Las motivaciones autorales cambian dependiendo de cada uno de los creadores que deciden emprender estas traslaciones y más, si cabe, cuando no nacen de la 
estrategia comercial o el franquiciado de una major de Hollywood o de los intereses de un sagaz productor para hacerse con los derechos de una obra gráfica cuya recepción y distribución sean apuestas casi seguras en los mercados del cine.

Se puede distinguir, objetivamente, que la materialidad obtenida en las últimas décadas a partir del uso y evolución de la tecnología CGI y las técnicas tridimensionales han favorecido la espectacularización y, además, facilitan los procesos de traslación de las narraciones gráficas más exigentes a nivel logístico, constituyendo un repertorio que en el apartado escenográfico consigue integrar de forma plausible los universos ficcionales de cómics y novelas gráficas de gran potencia visual y escénica.

Al margen de formatos, técnicas o procesos, las artes visuales como el cómic, el cine o los videojuegos plantean una sutil veladura que desdibuja las aplicaciones formales que las herramientas digitales han proporcionado, desplegando un potencial que parece ilimitado y en el que se nutren tanto la historieta como los relatos audiovisuales. En cualquier caso, al ahondar en el concepto de emulación en torno a las traslaciones, la misma se plantea como una pugna, puesto que el término «émulo» se define en su búsqueda por competir e imitar frente a otro y persigue superarlo. En esa línea se puede recurrir a la noción de la remediación, con la que Jay David Bolter y Richard Grusin (2000) plantean la capacidad de cada medio por converger y yuxtaponer con otros medios con los que rivaliza, exponiendo que resulta imposible generar un texto sin que se encuentre mediado por sustratos textuales precedentes. No obstante, la interesante idea de Bolter y Grusin de que los medios rivalicen resulta demasiado agresiva y beligerante, cuando no precaria cuando se plantea un análisis que no caiga de nuevo en el mal endémico de la jerarquización.

Así, cuando se emprende el trabajo comparatista no debería expresarse un planteamiento fundado en la oposición de objetos de estudio, sino como complemento funcional para rastrear las interacciones recíprocas que se generan a partir de un diálogo entre las artes y no una contienda. Conviene aplicarse y no caer en premisas restrictivas, incorporando «un aparataje riguroso para apelar al reconocimiento académico» (Altarriba, 2011: 10), ampliando el espacio de los estudios comparatistas y penetrar en el fecundo y, a veces, enmarañado camino que son los ámbitos de las transferencias de las narraciones gráficas en el medio audiovisual. 


\section{BIBLIOGRAFÍA CITADA}

AERTSEN, Víctor (2021), «De la línea clara al movimiento perpetuo: realismo y dinamismo en la adaptación cinematográfica de Las aventuras de Tintín de Steven Spielberg», Trasvases entre la literatura y el cine, 3, págs. 55-78.

Altarriba, Antonio (2011), «Introducción sobre el origen, evolución, límites y otros debates teóricos en torno a la historieta», ARBOR: Ciencia, Pensamiento y Cultura, 2 (Extra), págs. 9-14, DOI: $10.3989 /$ arbor.2011.2extran2111

BAILE LÓPEZ, Eduard (2020), «En el cómic nadie puede oír tus gritos: a propósito de las adaptaciones del cine al cómic», Quaderns de cine, 15 , págs. 25-43.

BOlter, Jay David y Grusin, Richard (2000), Remediation: Understanding New Media, Massachusetts, MIT Press.

BóRQUEZ, Néstor (2021), «De la novela gráfica al documental: el caso de María y yo», Trasvases entre la literatura y el cine, 3, págs. 79-100.

Constandinides, Costas (2010), From Film Adaptation to Post-Celluloid Adaptation: Rethinking the Transition of Popular Narratives and Characters Across Old and New Media, New York, Continuum.

FIELD, Syd (1995), El manual del guionista: ejercicios e instrucciones para escribir un buen guión paso a paso, Madrid, Plot.

Frezza, Gino (2017), La Máquina del Mito. En el Cine y el Cómic, Madrid, Ediciones Marmotilla.

FreZZA, Gino (2020), «STOP AND GO. Dialettiche del Movimento tra fumetto e cinema», Tebeosfera: Cultura Gráfica, 15, traducción de Francisco Sáez de Adana [En línea: https://www.tebeosfera.com/documentos/stop and go. diale ttiche del movimento tra fumetto e cinema.html Fecha de consulta: 05/02/2021]

Gaudreault, André y Marion, Philippe (2004), «Transécriture and Narrative Mediatics: The Stakes of Intermediality», en Robert Stam y Alessandra Raengo (eds.), A Companion to Literature and Film, Malden, Blackwell Publishing, págs. 58-70.

García-Reyes, David (2020), «Reescrituras en Soldados de Salamina o las sendas de la memoria: Desplazamientos de la literatura en el cine y en la narración figurativa», Trasvases entre la literatura y el cine, 2, págs. 271-291 [En línea: doi.org/10.24310/Trasvasestlc.vi2.9191 Fecha de consulta: 20/03/2021]

García Sánchez, Sergio (2000), Sinfonía gráfica: variaciones en las unidades estructurales y narrativas del cómic, Barcelona, Glénat. 
Gómez Rosado, Raquel (2010), «La fascinación del pixel», en AA.VV., Estéticas de la animación, Madrid, Fundación Luis Seoane/MAIA Ediciones, pp. 209-230.

Manovich, Lev (2001), The Language of New Media, Massachusetts, MIT Press.

McCloud, Scott (1994), Understanding Comics. The Invisible Art, New York, Harper Perennial.

Patinax, Maurice (1996) «Collectionner les bandes dessinées», en Moliterni, Claude, Mellot, Phillippe y Denni, Michel (eds.), Les Aventures de la BD, París, Gallimard, pp. 138-142.

Pons, Álvaro (2013), «La adaptación de cómics al cine en Francia y EEUU: Del homenaje artístico a la franquicia mercadotécnica», L'Atalante. Revista de estudios cinematográficos, 16, págs. 27-34.

REVERT, Jordi (2016), «Orígenes y fundamentos de la intermedialidad entre cine y cómic: una aproximación para la era digital», adComunica. Revista Científica de Estrategias, Tendencias e Innovación en Comunicación, 11, págs. 145-163 [En línea: http://dx.doi.org/10.6035/2174-0992.2011.9 Fecha de consulta: 07/04/2021]

Palacio, Manuel y De la Rosa, Emilio (1983), «Cómic y cine de animación», Neuróptica: estudios sobre el cómic, 1, págs. 71-78.

SÁNCHEZ-NAVARRO, Jordi (2020), La imaginación tangible. Una historia esencial del cine de animación, Barcelona, Editorial UOC.

SÁnCHEZ Noriega, José Luis (2018), Historia del Cine: Teorías, estéticas, géneros, Madrid, Alianza. Tercera Edición.

SEgER, Linda (1993), El arte de la adaptación, Madrid, Rialp.

Scott Fitzgerald, Francis, DefilipPis, Nunzio, Weir, Christina y CORnell, Kevin (2009), El curioso caso de Benjamin Button, Madrid, Gadir.

Stam, Robert (2014), Teoría y práctica de la adaptación, México, UNAM.

WRIGHT, Jean Ann (2006), Guionización y desarrollo de la animación: Desarrollar el guión para su venta, Andoain, Elsevier/Escuela de Cine y Vídeo.

Fecha de recepción: 27/04/21.

Fecha de aceptación: 12/05/21. 